Oper Orthop Traumatol 2015 · 27:154-154

DOI 10.1007/s00064-015-0364-1

Online publiziert: 12. April 2015

c) Springer-Verlag Berlin Heidelberg 2015

R. Hube ${ }^{1} \cdot$ T. Pfitzner ${ }^{2} \cdot$ P. von Roth ${ }^{2} \cdot$ H.O. Mayr ${ }^{1}$

${ }^{1}$ OCM-Klinik München

${ }^{2}$ Orthopädische Universitätsklinik, Charitè Universitätsmedizin Berlin

\title{
Erratum zu: Defektrekonstruktion in der Knieendoprothetik mit Wedges und Blöcken
}

In diesem Beitrag wurde der englische Titel leider falsch angegeben. Wir bitten, den korrekten Titel "Defect reconstruction in total knee arthroplasty with wedges and blocks" zu beachten und den Fehler zu entschuldigen.

\section{Korrespondenzadresse}

PD Dr. R. Hube

OCM-Klinik München

Steiner Str. 6, 81369 München

robert.hube@ocm-muenchen.de 